\title{
EMPREENDEDORISMO E MARKETING: UM ESTUDO NO SEGMENTO DE BARES DE BELO HORIZONTE/MG
}

\author{
Jefferson Rodrigues Pereira ${ }^{1}$, Leonardo Benedito Oliveira Rezende ${ }^{1}$, Caissa Veloso e Sousa ${ }^{1}$, \\ Sarah Lopes Silva ${ }^{1}$, Eduardo Roberto Batista ${ }^{1}$ \\ ${ }^{1}$ Faculdade Novos Horizontes \\ jeffersonrodrigues@live.com, leorezendelo0@gmail.com, valeriaananda@hotmail.com, \\ caissaveloso@yahoo.com.br, sarah.lop@gmail.com, eduardolit@gmail.com
}

\begin{abstract}
Resumo
Atualmente, o Brasil é um dos países com o sistema de distribuição de renda mais falhos do mundo, apesar do ressaltado progresso da última década. Como tentativa de corrigir falhas no sistema governamental, alguns atores sociais começam a atuar com o intuito de modificarem esta perspectiva, no que tange aos interesses individuais, essa figura recebe o nome de empreendedor. Mediante o cenário previamente exposto, o presente estudo foi desenvolvido a fim de analisar o elo de interseção entre o empreendedorismo e o marketing no segmento de bares da cidade de Belo Horizonte/ MG, a terceira maior capital do Brasil. Atualmente, o segmento de bares brasileiro, responsável por mais de $23 \%$ do total de empreendimentos no país, é caracterizado pelo elevado nível de concorrência e dinamicidade. Nesse ambiente, o presente estudo tem como objetivo geral identificar os principais desafios de um empreendedor do ramo de bares da cidade de Belo Horizonte/MG. Para tal, realizou-se uma pesquisa de caráter qualitativo descritivo, com doze empreendedores do segmento de bares da cidade de Belo Horizonte/MG, Brasil. A análise de dados foi pautada na análise de conteúdo temática, à luz das proposições de Bardin (2006). Dentre os resultados alcançados destaca-se que os maiores desafios dos empreendedores estão relacionados à falta de um planejamento estratégico e a uma estrutura deficiente de marketing. Ressalta-se, ainda, que a maioria dos empreendedores analisados é classificada como empreendedor por necessidade.
\end{abstract}

Palavras-chave: Estratégia. Marketing. Empreendedorismo.

\section{ENTREPRENEURSHIP AND MARKETING: A STUDY IN THE SEGMENT OF BARS IN THE CITY OF BELO HORIZONTE/MG.}

\begin{abstract}
Currently, Brazil is among the countries with the most flawed income distribution in the world, despite the prog ress made throughout the last decade. In an attempt to correct some flaws in the governmental system, some social actors come into play in order to change this reality, they are so called entrepreneurs. Taking in account the previously exposed scenario, this study was developed to analyze the intersection link between entrepreneurship and marketing in the segment of bars in the city of Belo Horizonte, Brazil's third largest city. Nowadays, the segment of Brazilian bars, which is responsible for over $23 \%$ of all enterprises in the country, is marked by a high level of competition and dynamism. In this environment, this study has the general objective to identify the main challenges of bars branches of the entrepreneurial city of Belo Horizonte. To meet this end, a descriptive qualitative study was conducted, with twelve entrepreneurs from the segment of bars in the city of Belo Horizonte / MG, Brazil. All data analysis was based on thematic content analysis, in the light of the propositions of Bardin (2006). Among the results achieved we highlight that the greatest challenges to entrepreneurs are related to lack of strategic planning and R. Eletr. do Alto Vale do Itajaí - REAVI, v. 4, n. 5, p. I- F, mar., 2016. ISSN 2316-4190, DOI: 10.5965/2316419004052015090
\end{abstract}


Universidade do Estado de Santa Catarina

Centro de Educação Superior do Alto Vale do Itajaí

poor marketing structure. It is worth saying that most of the analyzed entrepreneurs were classified as entrepreneurs by necessity.

Keywords: Strategy. Marketing.Entrepreneurship.

\section{Introdução}

Atualmente, o Brasil é um dos países com o sistema de distribuição de renda mais falhos do mundo, apesar do ressaltado progresso das últimas décadas (DEGEN, 2009). Este cenário, segundo Alves (2009), pode ser compreendido como um reflexo da intensificação de insegurança de classes e precarização do trabalho, o que pode, em determinada instância, se relacionar a baixa produtividade do trabalho.

Como resposta a este contexto, na última década, identifica-se um aumento de ações empreendedoras no país. De acordo com pesquisa realizada pelo Global Entrepreneurship Monitor (GEM), em 2012, cerca de 30,2\% da população adulta brasileira está diretamente envolvida com o empreendedorismo. Esse percentual representa mais de 36 milhões de pessoas, com idades entre 18 e 64 anos.

Para Festinalli (2003), no Brasil, o ato de empreender está diretamente relacionado à necessidade de sobrevivência e geração de renda da população uma vez que, nesse aspecto, as políticas públicas se mostram ineficientes.

Sobre esse cenário, o Instituto Brasileiro de Geografia e Estatística (IBGE) ressalta a importância de ações empreendedoras individuais para o desenvolvimento do país. Segundo o Instituto, micro e pequenas empresas atualmente representam cerca de $99 \%$ do total de empresas formais do país, gerando em média $57 \%$ do total de empregos ofertados, além de corresponder a mais de $27 \%$ do total da massa salarial (IBGE, 2012).

Mediante a este contexto importa, no âmbito brasileiro, compreender as motivações de um empreendedor individual, dado que esse ator fornece grande contribuição para o desenvolvimento socioeconômico do país.

Para Oliveira (2010, p. 21), o "empreendedorismo, atualmente, é o método mais eficiente para ligar a ciência ao mercado, criando empresas e levando novos produtos e serviços ao mercado". Considerando essa perspectiva deve-se considerar os empreendimentos resultantes de empresas que tiveram sua gênese em processos inovadores e aqueles resultantes de incubadoras sediadas nas universidades. Nesse sentido, o empreendedor pode ser compreendido como a figura responsável por identificar oportunidades e introduzir inovações ao mercado, o que o caracteriza o que Dolabela (1999) chama de agente de mudanças.

Para casos específicos de empreendedores de alguns segmentos, como o dos bares, por exemplo, inicialmente deve-se destacar que o setor que possui forte tendência de crescimento no Brasil. Isso provavelmente devido a sua dinamicidade (a maioria deles possui ciclo de vida relativamente curto), informalidade e uma atuação no campo relacionado ao lazer do consumidor, que na maioria das vezes quando satisfeito, se mostra fiel (OLIVEIRA, 2010).

Em uma segunda instância ressalta-se o fato de que, devido a limitações estruturais do empreendimento, unido a um capital escasso, a maioria dos empreendedores de bares não possui uma plataforma de marketing estabelecida, fato que reduz sua longevidade empresarial.

Nesse sentido, a presente pesquisa tem como questionamento norteador: Quais são os principais desafios de um microempreendedor, atuante no segmento de bares, para se estabelecer de forma duradoura junto ao mercado?

Este estudo teve por objetivo geral identificar os principais desafios dos empreendedores do ramo de bares da cidade de Belo Horizonte/MG, para se estabelecer em um mercado competitivo e dinâmico. 
Como objetivos específicos pretende-se: a) identificar quais são as principais dificuldades, na percepção dos empreendedores, para o estabelecimento e manutenção no mercado de bares e restaurantes; b) identificar as falhas estruturais do segmento de bares da localidade; c) identificar 'gaps' nas estratégias de marketing dos empreendedores pesquisados.

$\mathrm{O}$ artigo está dividido em cinco seções. A primeira compreende esta introdução. A segunda seção apresenta o referencial teórico que suporta a discussão ora proposta, seguida da metodologia do estudo. A quarta seção apresenta a análise de dados. Por fim, são apresentadas as considerações finais do estudo.

\section{Referencial teórico}

Esta seção apresenta o referencial teórico contemplando os temas: empreendedorismo; perfil do empreendedor; característica dos pequenos negócios no Brasil; estratégias de marketing; e, marketing e qualidade dos serviços.

\subsection{Empreendedorismo}

Oliveira (2010) destaca que o desenvolvimento do empreendedorismo como uma área da administração pode representar um período relevante na transição para uma fase da civilização contemporânea.

A palavra empreendedorismo, segundo Dolabela (1999), é um neologismo oriundo da tradução da palavra entrepreneurship, para a qual o principal significado é atribuído para designar estudos relativos ao perfil de pessoas inovadoras e visionárias, que são capazes de moldar a realidade em que vivem, criando ou até mesmo alterando um processo.

$\mathrm{Na}$ literatura identifica-se que o conceito ainda está em processo de discussão, por óticas aparentemente diferenciadas, porém relacionadas. Duas delas são mais sobressalentes: de um lado uma ótica economista de que o empreendedorismo está diretamente associado à inovação; por outro lado uma ótica comportamentalista que se concentra nos aspectos criativo e intuitivo (FILION, 1999).

Atualmente a ótica mais aceita do empreendedorismo relaciona-se ao fato do empreendedor ser uma figura que viabiliza a destruição de uma ordem social já consolidada pela introdução de produtos e serviços inovadores, pela estruturação de novas formas de organização ou ainda pela utilização de novos recursos, processos ou materiais (STEVENSON e GUMPERT, 1985; SCHUMPETER, 1996; FILION, 1999; DORNELAS, 2001; OLIVEIRA, 2010).

Segundo Dornelas (2001, p. 65), o empreendedor pode ser visto como:

Aquele que destrói a ordem econômica existente pela introdução de novos produtos e serviços, pela criação de novas formas de organização ou pela exportação de novos recursos materiais. O empreendedor é o responsável pelo processo de destruição criativa, sendo o impulso fundamental que aciona e mantém em marcha o motor capitalista, constantemente criando novos produtos, novos métodos de produção, novos mercados e implacavelmente, sobrepondose aos antigos métodos menos eficientes e mais caros.

Tem-se por premissa que o empreendedorismo é o nome que se atribui às atitudes e ao perfil comportamentalista do empreendedor, quanto pessoa, ou seja, o empreendedor é o agente de mudanças do empreendedorismo, sendo o responsável pelo ato de empreender (SCHUMPETER, 1996).

\subsection{Perfil empreendedor}


De acordo com Rodrigues (2008) existe uma série de aspectos intrínsecos à figura do empreendedor, sendo ele um agente de mudanças. Ainda segundo a autora, os empreendedores são peritos capazes de identificar, explorar e comercializar oportunidades, sendo comum a eles a capacidade de identificar e de solucionar problemas que outros indivíduos ainda não perceberam, considerando formas inovadoras de abordar o cotidiano e perspectivar o futuro.

Segundo Dolabela (1999, p. 76):

Os empreendedores são visionários, dotados de ideias realistas e inovadoras, baseados no planejamento de uma organização, intervêm no planejado e propõem mudanças. O empreendedor desenvolve um papel otimista dentro da organização, capaz de enfrentar obstáculos internos e externos, sabendo olhar além das dificuldades, com foco no melhor resultado.

Alguns estudos acerca do perfil do empreendedor indicam como principais características a perseverança, o desejo de alterar o fluxo de sua vida, a competitividade, a capacidade de assumir riscos, a autoestima, o forte desejo de vencer, a criatividade, a autoconfiança, a capacidade de identificar tendências futuras e a flexibilidade (STEVENSON e GUMPERT, 1985; SCHUMPETER, 1996; FILION, 1999; KUEMMERLE, 2002; RODRIGUES, 2008; OLIVEIRA, 2010).

Ressalta-se que na literatura existe uma concepção do empreendedor nato, ou seja, aquele indivíduo que possui intrínsecas a ele as características anteriormente descritas. Contudo, o fato dele ser ente um social, que vive em constante processo de socialização, pode-se dizer que suas caraterísticas empreendedoras podem sofrer influências, principalmente, do grupo familiar, do nível de estudo, da formação e prática (MINER, 1997; OLIVEIRA, 2010).

Nesse contexto, importa destacar que o GEM, dentre suas diversas variáveis de análise, propõe identificar os motivos da atividade empreendedora. Segundo o GEM (2011), a atividade empreendedora pode ocorrer por dois motivos alternativos e, consequentemente, excludentes: a oportunidade ou a necessidade. Nesse sentido, o empreendedor por oportunidade pode ser visto como o indivíduo que se envolve com o empreendedorismo "por ter identificado uma oportunidade de negócio que pretende perseguir" (GEM, 2011, p. 89). Já o empreendedor por necessidade pode ser considerado aquele indivíduo que empreende "por não ter outra opção de trabalho" (GEM, 2011, p. 89).

Este posicionamento ainda pode ser observado nos relatos outros autores (WILLIAMS, 2008; BLOCK e SANDNER, 2009; BLOCK e WAGNER, 2010), segundo os quais, na atividade empreendedora, o indivíduo pode ser motivado por oportunidade ou necessidade, sendo essas variáveis antagônicas, ou seja, não ocorrem paralelamente.

Contudo, Vale, Corrêa e Reis (2014) ressaltam que os motivos 'oportunidade' e 'necessidade' não são variáveis necessariamente excludentes, dado que "um indivíduo que se sente compelido a abrir um empreendimento por falta de alternativa ou por necessidade de sobrevivência pode, eventualmente, ficar mais atento a oportunidades" (VALE; CORRÊA e REIS, 2014, p.323).

No âmbito acadêmico e científico, Dolabela (1999) afirma que a construção de um perfil empreendedor está relacionada diretamente à ação, sendo por situações que contribuem para sua execução. Nesse sentido, citam-se duas características que notavelmente incidem nesse processo, sendo a primeira a natureza da ação, busca por fazer algo novo por meio da modificação de processos ou produtos. E a segunda, relaciona-se a inexistência ou falta de controle sobre a forma como é executada a ação, ou até mesmo recursos necessários para o desenvolvimento da ação almejada (DOLABELA, 1999).

\subsection{Características dos pequenos negócios no Brasil}


De acordo com a Lei Geral da Micro e Pequena empresa (Lei n 123/2006), pode ser considerado um pequeno negócio (BRASIL, 2006):

- Microempreendedor individual (MEI) - receita bruta individual de até R\$ 60 mil;

- $\quad$ Microempresa (ME) - receita bruta anual de R\$ 60 mil a R $\$ 360$ mil;

- $\quad$ Pequena Empresa - receita bruta anual de R \$ 360 mil a R \$ 3,6 milhões.

De acordo com o Serviço Brasileiro de Apoio às Micro e Pequenas Empresas (SEBRAE) em julho de 2013, os pequenos negócios já representavam 99\% do total de empresas ativas do país.

Atualmente, o segmento é responsável pela geração de $25 \%$ de todo o Produto Interno Bruto (PIB) nacional, além de 52\% do saldo dos empregos formais, bem como $70 \%$ do total de novas vagas de empregos gerados mensalmente, contribuindo com $40 \%$ da massa salarial e sendo ainda responsável por $1 \%$ das importações do país (SEBRAE, 2013).

De acordo com o relatório do SEBRAE 'Pequenos Negócios no Brasil', do primeiro semestre de 2013, na divisão das micro e pequenas empresas por setores, uma a cada duas pequenas empresas brasileiras atuam no segmento do comércio, representando $49 \%$ do total. O restante se divide em $31 \%$ do setor de serviços, $15 \%$ de indústrias e $5 \%$ no setor de construção civil (SEBRAE, 2013).

Contudo, destaca-se que a distribuição geográfica dos pequenos negócios no país se mostra de forma desigual. Do total de 7,6 milhões de empreendimentos optantes pelo Supersimples (Regime Especial de Tributação para os Pequenos Negócios), 49\% deles se concentram na região sudeste, $19 \%$ na região sul, $19 \%$ na região nordeste, $8 \%$ na região centro-oeste e $5 \%$ na região norte (SEBRAE, 2013). Salienta-se que são os empreendedores individuais, pequenos e micro empreendedores, aqueles que optam por esse tipo de tributação. Nesse aspecto, identificase uma concentração desse tipo de empreendimentos na região sudeste do país, que concentra estados de PIB relativamente significativos para o país.

\subsection{Estratégias de marketing}

As estratégias de Marketing são importantes para a definição do posicionamento competitivo de uma organização, além de serem também especialmente válidas para os tempos de crise econômica, na qual a diferenciação das estratégias pode determinar o futuro da organização em uma competição de mercado (KOTLER, 1998).

Nesse contexto, Hunt (2010) destaca que a utilização do composto de marketing, referindo-se a um conjunto de ferramentas estratégicas que a empresa utiliza para perseguir seus objetivos de mercado, se apresenta como aspecto fundamental para que ocorra harmonia e bom funcionamento das estratégias de captação e retenção dos clientes.

Nesse sentido, a inclusão do marketing na adoção das estratégias organizacionais se configura como uma premissa, sendo esta uma importante ferramenta para se alcançar os objetivos criados pelas organizações. Neste caso, a empresa deve também ser organizada por meio de decisões estratégicas, reestruturando funções e departamentos, de acordo com o mercado e as suas necessidades (HITT; IRELAND e HOSKISSON, 2011; PETER e OLSON, 2009).

Para Mintzberg (2000), o papel do marketing em relação a estratégia da organização é dependente da estratégia que a empresa cria, de acordo com a sua estrutura e conveniência. Por outro lado o inverso também ocorre, na qual a "tarefa do diretor de marketing é identificar oportunidades e preparar estratégias e programas de marketing” (KOTLER, 1998, p. 646). Diante de tal exposição o termo planejamento estratégico consolida a dependência mútua entre o marketing e a estratégia das empresas. 


\section{REAVI}

Universidade do Estado de Santa Catarina

Centro de Educação Superior do Alto Vale do Itajaí

Nesse aspecto, segundo Czinkota (2001, p. 30), “o conceito de marketing evoluiu para o conceito de marketing estratégico, definido como a missão da corporação de buscar uma vantagem competitiva sustentável satisfazendo as necessidades dos clientes".

\subsection{Marketing e qualidade de serviços}

Um dos principais pontos para compreensão do marketing de serviços é identificar qual sua distinção do marketing de produto.

Segundo Baterson e Hoffman (2003), o marketing de serviço difere de produto principalmente em função das especificidades dos serviços. Existem várias definições para o termo serviço, mas todas levam em consideração suas características principais, ou seja, a intangibilidade e o consumo simultâneo. Portanto, o serviço é entendido por algo não tangível no qual a consumo e a prestação ocorrem simultaneamente.

Nesse sentido, torna-se possível inferir que, devido as suas características, torna-se complicado definir um serviço puro, ou seja, aquele que não vem acoplado a um produto, mesmo que de valor secundário.

Assim como a definição de serviço, a mensuração de qualidade do mesmo assume um grau ainda mais elevado de complexidade. De acordo com Miguel e Salomi (2004) existem seis modelos principais na literatura que permitem avaliar a qualidade de um serviço, porém, todos estão relacionados à percepção de qualidade, diferindo uns dos outros pela ótica de análise. Este fato leva a inferir que mensuração de qualidade está sujeita a ação de fatores psicológicos, temporais e hedônicos.

Como auxílio para a mensuração da qualidade de serviços, alguns autores utilizam cinco dimensões, que por sua vez atribuem características mais tangíveis aos serviços (FITZSIMMONS e FITZIMMONS, 2010), são elas:

- Confiabilidade: relacionado ao vínculo de confiança estabelecido no ato da prestação do serviço.

- Receptividade ou responsividade: aspectos relacionados à prontidão no atendimento.

- Segurança: esta dimensão reúne uma série de variáveis, que em sua grande maioria estão relacionados a conhecimento técnico e a capacidade de se transmitir confiança e confidencialidade.

- Empatia: está ligada a capacidade de demonstrar interesse e oferecer atenção personalizada aos clientes.

- Aspectos tangíveis: relacionada aos aspectos físicos que compõem o ambiente no qual a prestação de serviço está sendo realizada.

O autor ainda reitera que o grau de importância atribuído a cada dimensão varia em função das características pessoais de cada indivíduo.

Em suma, torna-se possível dizer que marketing e qualidade de serviços são variáveis diretamente relacionadas com a subjetividade, ou seja, cada pessoa pode ou não ter uma percepção diferente de qualidade, principalmente, quando relacionada a serviços.

Segundo Bateson e Hoffman (2003), na tentativa de se mensurar a qualidade de um serviço, deve-se levar em consideração que, para este caso, a qualidade é um fator relacionado à satisfação, mas não equivalente. Ou seja, "a percepção de qualidade de um serviço é medida pela resultante entre a expectativa e a percepção de valor do cliente" (BATERSON e HOFFMAN, 2003, p. 63).

A partir da intercessão das visões de Bateson e Hoffman (2003) e Fitzsimmons e Fitzsmmons (2010), identifica-se que o cliente, em seu processo individual de mensuração de qualidade de um serviço, utiliza as dimensões do serviço como base de confrontação entre a expectativa e a percepção de valor que é atribuído ao serviço. 
Nesse sentido, para Zeithaml, Berry e Parasuraman (1988), se as expectativas do cliente forem igualadas com o serviço que de fato o foi entregue, então a avaliação da qualidade do serviço será positiva. Ou seja, "se o serviço percebido é igual ou superior ao serviço esperado, o consumidor fica satisfeito" (BATESON e HOFFMAN, 2003, p. 49).

Em outras palavras, pode-se dizer que a qualidade de um serviço é medida pela resultante entre as expectativas do cliente e sua percepção de valor do serviço que lhe foi prestado.

Alguns autores ainda destacam a existência de dois tipos de expectativas, a desejada e a adequada, sendo a desejada relacionada ao que o cliente acredita ser um serviço de qualidade. Esta leva em consideração as dimensões consideradas na avaliação do cliente (ZEITHAML; BERRY e PARASURAMAN, 1988; BATESON e HOFFMAN, 2003; FITZSIMMONS e FITZSIMMONS, 2010).

A adequada, por sua vez, aponta um serviço que diverge da expectativa desejada, porém serve como um termômetro de qualidade, uma vez que nivela o ponto que o cliente considera o nível de qualidade suficiente para que ele não fique insatisfeito (ZEITHAML; BERRY e PARASURAMAN, 1988; BATESON e HOFFMAN, 2003; FITZSIMMONS e FITZSIMMONS, 2010). Nesse sentido, conforme Zeithaml, Berry e Parasuraman (1988, p. 7) "a lacuna oriunda da variação entre estas duas expectativas é chamada Zona de Tolerância".

\section{Metodologia}

A presente pesquisa é caracterizada como um estudo de caso de caráter qualitativo. Para Triviños (1992), o estudo de caso se classifica como um dos mais relevantes para a pesquisa qualitativa. É utilizado em diferentes áreas do conhecimento para fins de análise, estudo, tratamento ou acompanhamento. É conveniente para responder a perguntas 'como' e 'por que' (YIN, 2010), a fim de comportar uma análise intensa e extenuante de uma realidade determinada, buscando possibilitar profundo e minucioso conhecimento (GIL, 1999; TRIVIÑOS, 1992).

Segundo Denzin e Lincoln (2010), este tipo de pesquisa promove a interdisciplinaridade entre campos, temas e linhas de raciocínio aparentemente divergentes (DENZIN e LINCOLN, 2010). Pode-se dizer que o ideal de um estudo qualitativo é que seja rico e abrangente. Nesse sentido, a pesquisa qualitativa tem como foco criar uma percepção acerca do observador ao contexto no qual se insere, criando uma visão clara de como se situa o ambiente da análise por meio dos dados coletados (CRESWELL, 2007).

Como objeto de estudo foram analisados doze bares localizados da cidade Belo Horizonte/MG, Brasil. A técnica de coleta de dados se deu por meio de entrevistas semiestruturadas, com os empreendedores dos estabelecimentos. Segundo Denzin e Lincoln (2010), nesse tipo de entrevista o entrevistador possui flexibilidade para alterar sua estrutura, quando lhe convier, em busca de dados que julgue de maior relevância.

Para análise dos dados optou-se pela análise de conteúdo temática. Para Bardin (2006), a análise de conteúdo compreende as iniciativas de explicitação, sistematização e demonstração do conteúdo de mensagens, com o objetivo de se realizarem deduções lógicas e justificadas sobre a origem dessas mensagens (quem as emitiu, em que contexto e/ou quais efeitos se pretende causar por meio delas).

Nesse sentido, a análise de conteúdo se desenvolveu tendo por base as seguintes dimensões: Dados descritivos; As motivações e a formação; O cliente; Demandas e desafios e, Marketing e estratégia.

\section{Apresentação e análise de resultado}


Universidade do Estado de Santa Catarina

Centro de Educação Superior do Alto Vale do Itajaí

As categorias previamente estabelecidas no roteiro de entrevistas foram confirmadas durante as entrevistas e estão descritas em análise nas subseções que seguem.

\subsection{Dados descritivos}

Na presente dimensão são apresentadas as características do grupo analisado e dizem respeito a: sexo, faixa etária, escolaridade, tempo de vida na empresa e faturamento bruto.

\begin{tabular}{c|c|c|c|c}
\hline Entrevistado & Sexo & Faixa etária (anos) & Escolaridade & Tempo de atuação \\
\hline E1 & Masculino & 18 a 27 & Superior & 8 anos \\
\hline E2 & Masculino & 28 a 37 & Médio & 5 anos \\
\hline E3 & Feminino & 28 a 37 & Médio & 2 anos \\
\hline E4 & Masculino & 18 a 27 & Médio & 2,5 anos \\
\hline E5 & Masculino & 38 e 47 & Médio & 8 meses \\
\hline E6 & Masculino & 28 a 37 & Médio & 3 anos \\
\hline E7 & Feminino & 28 a 37 & Médio & 1,3 anos \\
\hline E8 & Feminino & 38 e 47 & Médio & 4 anos \\
\hline E9 & Feminino & 38 e 47 & Médio & 1 ano \\
\hline E10 & Masculino & 18 a 27 & Médio & 1,6 anos \\
\hline E11 & Masculino & Acima de 60 & Fundamental & 11 anos \\
\hline E12 & Feminino & 28 a 37 & Médio & 3 anos \\
\hline Tabela $1-$ & Descrição & rontros
\end{tabular}

Tabela 1 - Descrição dos entrevistados (Desenvolvido pelos autores, 2015)

Destaca-se ainda que dois dos estabelecimentos analisados possuem gestão familiar (E1 e E12).

Quanto ao faturamento bruto anual, os estabelecimentos objetos de análise se classificam da seguinte forma, de acordo com a Lei Geral da Micro e Pequena empresa (Lei $n^{\circ}$ 123/2006):

- E2, E3, E4, E5, E6, E7, E9, E10, E11 e E12: Microempreendedor Individual - MEI (receita bruta individual de até $\mathrm{R} \$ 60 \mathrm{mil}$ );

- $\quad$ E1 e E8: Microempresa - ME (receita bruta anual de R \$ 60 mil a R \$ 360 mil).

\subsection{As motivações e a formação}

A presente dimensão analisou o motivo pelo qual os empreendedores montaram um negócio próprio.

Inicialmente, destaca-se que para os entrevistados E1, E5, E6, E11 e E12, o interesse pelo segmento de bares se deu devido à experiência de um trabalho anterior.

Ressalta-se ainda que um aspecto comum no posicionamento de nove dos entrevistados relaciona-se a necessidade de sustento próprio e da família.

Eu precisava dar o que comer para minha família e conseguir um emprego que me garantisse isso estava difícil, aí resolvi arriscar (E11).

Sempre gostei de cozinhar, mas o que falou mais alto foi que eu precisava cuidar dos meus filhos. Imagina só: sozinha tendo três crianças para sustentar (E8). 
Universidade do Estado de Santa Catarina

Centro de Educação Superior do Alto Vale do Itajaí

Nesse sentido, salienta-se que no relato de onze dos entrevistados os motivos para se abrir o negócio estava, primeiramente, relacionado à necessidade de suprir uma demanda básica individual e da família, caracterizando-os, portanto, como empreendedores por necessidade (FILION, 1999; DORNELAS, 2001; OLIVEIRA, 2010). Apenas o entrevistado E7 pode ser considerado empreendedor por oportunidade, uma vez que o mesmo percebeu uma possibilidade de sucesso no segmento na localidade na qual se instalou (FILION, 1999; DORNELAS, 2001; OLIVEIRA, 2010).

Nesse ambiente, sublinham-se os apontamentos de E12, segundo a qual, as motivações que a fizeram iniciar e permanecer no ramo de bares está relacionado a facilidade de comunicação e prazer em lidar com o público, bem como a percepção de uma área que possui grande expectativa de expansão.

As pessoas precisam relaxar do ambiente de trabalho que cada vez é mais estressante. Ademais, Belo Horizonte é considerada a capital de barzinhos, então porque não investir nesse ramo? (E12).

Nesse sentido, salienta-se as características apontadas por Rodrigues (2008), ao afirmar que existe uma série de aspectos intrínsecos à figura do empreendedor, sendo ele um agente de mudanças. Ainda segundo a autora, os empreendedores são peritos capazes de identificar explorar e comercializar oportunidades, sendo comum a eles a capacidade de identificar e solucionar problemas, que outros indivíduos ainda não perceberam, considerando formas inovadoras de abordar problemas e perspectivas da realidade.

Em um segundo momento, analisou-se como os entrevistados se preparam para as demandas do negócio, ou seja, se estão se qualificando para prestar seus serviços.

Em um primeiro momento, destaca-se que apenas os entrevistados E1, E7 e E8 afirmam estar em um constante processo de qualificação.

Meus pais tinham o negócio e não tinham estudo, mas investiram na minha formação como administrador para eu assumir o negócio da família (E1).

Outros dois entrevistados afirmam ter realizado cursos de formação profissional periodicamente em alguns órgãos de desenvolvimento profissional, como o Serviço Nacional de Aprendizagem Comercial (SENAC) e o SEBRAE. Contudo, não foi possível determinar o número de cursos realizados e o controle das disciplinas cursadas. Como forma de aprendizado foram mencionados o aprendizado informal e o aprendizado por meio de livros de receitas e utilização da internet.

Apesar da falta de formação específica no setor, todos os empreendedores consideram importante o investimento em educação, além da formação profissional e conhecimento na área escolhida para empreendimento.

\subsection{0 cliente}

A carteira de clientes é definida pelos entrevistados como heterogênea, pois os frequentadores dos estabelecimentos mesclam-se entre as classes A e C.

De acordo com os entrevistados, as idades dos frequentadores variam, principalmente, entre dezoito e trinta anos, sendo na maioria jovens universitários. Outro ponto a ser ressaltado é a predominância de clientes do gênero feminino. Essas características demandam do empresário maior capacidade de interação, empatia e inovação. 
Aqui vêm muitos jovens, saem da faculdade e passam aqui, às vezes no intervalo mesmo. Então tentamos fazer um atendimento voltado para o público mais jovem, procuramos atender eles de forma mais descontraída (E1).

Vêm muitos jovens e jovens você já viu... gostam de coisas diferentes, de interagir, criam um laço de amizade mesmo com todos os funcionários do bar. Chega ao ponto dos garçons já decorarem seus pedidos mais frequêntes e isso é ótimo, eles se sentem em casa (E8).

Nesse sentido, sublinha-se, nos relatos de todos os entrevistados, o empenho empreendido para superar a expectativa dos clientes e fidelizá-los, fato que corrobora o posicionamento de Bateson e Hoffman (2003).

\subsection{Demandas e desafios}

A qualidade foi considerada por todos os entrevistados como um item indispensável na execução do negócio.

O empreendimento não pode apresentar uma aparência desleixada. A qualidade no atendimento também é primordial, pois um cliente mal atendido repassa a outras pessoas a sua insatisfação e a chance deste cliente voltar ao negócio é quase nula (E1).

Se não for oferecido um serviço com qualidade, seja no produto como tira gosto, uma bebida gelada ou no atendimento como rapidez no atendimento e cortesia do garçom, eu não tenho nada. Pode ser o melhor bar do mundo o cliente não vai retornar (E3).

Destaca-se nos relatos de E1, E5, E6, E8, E10 e E12 fatores relacionados a infraestrutura que, segundo os quais, deve espelhar essa qualidade, considerando que a primeira impressão do cliente deve ser positiva, para isso, se torna importante uma cozinha equipada e higienizada, banheiros limpos, mesas e cadeiras em perfeito estado, pintura nova.

Outro item importante é o preço que precisa ser coerente com o produto e com o mercado.

É necessário que o empresário faça uma pesquisa de mercado para verificar os preços praticados por seus concorrentes e após fazer o cálculo do custo total do produto, averiguar a possibilidade de oferecer um preço diferenciado dos demais (E6).

Além do preço diferenciado é importante que o empresário seja transparente com os seus clientes, esse comportamento é o que possibilitará estabelecer laços de confiança do cliente no empreendimento. Para isso, se faz importante a presença do empresário dentro do estabelecimento, fato que coincide com os apontamentos de Dolabella (1999), uma vez que a confiança e a qualidade são determinantes no futuro do negócio.

É o olho do dono que engorda o gado, o empresário não pode simplesmente abrir o bar e deixar por conta de seus empregados (E3).

No que se refere aos desafios relacionados ao empreendimento identificaram-se cinco pontos de maior incidência no relato dos entrevistados, a saber: 
I. Falta de mão de obra qualificada: pode gerar impactos diretos na percepção de qualidade do cliente.

II. Dificuldade de encontrar bons fornecedores para o negócio a um preço justo: fator que pode impactar negativamente na qualidade do serviço e preços praticados.

III. Encargos trabalhistas e elevada carga tributária: impactos no resultado final da empresa, além de estimular o trabalho informal.

IV. A legislação foi avaliada como um desafio constante, visto que nove dos entrevistados não possui conhecimento sobre legislação e regulamentações do setor.

V. Falta ou fragilidade de um planejamento estratégico de marketing: impactos na longevidade do empreendimento.

\subsection{Marketing e estratégia}

A presente dimensão tem como objetivo analisar aspectos relacionados ao marketing e a estratégia dos empreendimentos, objeto deste estudo.

Inicialmente destaca-se que apenas um dos entrevistados possui um planejamento estratégico estruturado, que contemple a empresa em sua totalidade.

Não possuo um planejamento estruturado. Eu reparo erros que cometi e fico de olho em estabelecimentos que eventualmente vou, pra quem sabe, adotar uma forma melhor de fazer as coisas (E1).

Identificou-se, ainda, que os demais empreendedores trabalham em um sistema de correção de falhas explícitas em algum momento de sua trajetória.

Ao serem questionados acera do planejamento estratégico, seis entrevistados disseram que o planejamento é diário e salvo na mente.

Aqui meu planejamento é diário, guardo tudo na cabeça e sempre deu certo (E11).

No que se refere ao marketing de relacionamento, apenas E1 afirmou possuir uma ferramenta estruturada de análise e retenção de clientes. $O$ restante dos empreendedores dos estabelecimentos afirmam que percebem no dia a dia o que agrada ou não o consumidor.

A gente percebe alguma se coisa realmente agrada ou não agrada o cliente. Tem também aqueles que são mais chegados, aí peço sugestões de coisas que poderiam melhorar (E6).

Não precisa de ferramenta nenhuma, estou aqui todos os dias, dá pra ver muito bem se o cliente ficou satisfeito ou não (E9).

Destaca-se uma preocupação em melhorar o atendimento, as condições físicas do negócio, além da criação de novos pratos para o cardápio e enquadramento às novas demandas, como o oferecimento do cardápio em Braille (exigência da legislação sobre o setor).

Quanto à percepção do negócio nos próximos cinco anos, todos os empreendedores mencionaram o anseio de expansão do negócio, entretanto, E2, E3, E4, E9, E10 e E11 não possuem nenhum indício de planejamento quanto a este quesito.

Não tenho um planejamento estratégico muito bem definido não. O que eu quero é melhorar as estruturas, ampliar, contratar mais gente, não sei ainda como, só sei que quero (E6). 
Nesse sentido destaca-se que, apesar do anseio de expansão do negócio, a maioria dos entrevistados não possui um planejamento estratégico de marketing formalizado, fato que pode comprometer o atingimento dos objetivos da organização, contrapondo, consequentemente, o posicionamento de alguns autores (HITT; IRELAND e HOSKISSON, 2011; PETER e OLSON, 2009).

Diante do contexto apresentado, a próxima seçao se dispõe a apresentar as considerações finais sobre o estudo.

\section{Considerações Finais}

O presente estudo buscou identificar os principais desafios de um empreendedor do ramo de bares da cidade de Belo Horizonte/MG.

Dentre os principais resultados verificou-se que a maioria dos empreendedores analisados pode ser classificada como empreendedor por necessidade, ou seja, aquele que empreende na tentativa de solucionar um problema social em que se encontra e por isso cria uma nova alternativa de sustento para si e sua família.

Entre os maiores desafios enfrentados pelos entrevistados destacam-se a falta de um planejamento estratégico e uma estrutura deficiente de marketing. Contudo, devido as dimensões dos empreendimentos analisados, apesar de ser aconselhável, não se pode exigir que o empreendedor possua um planejamento de marketing robusto, principalmente se levado em consideração que se trata de um empreendedor por necessidade.

Identificaram-se como pontos fortes dos empreendimentos fatores como o interesse por prestar atendimento adequado e o relacionamento interpessoal, que se estruturam entre clientes e organização.

A maioria dos empreendedores em questão possui uma visão simplificada do processo de gestão, porém, ainda assim identificou-se a presença de traços que designam a figura empreendedora. Nesse sentido, torna-se possível verificar que os entrevistados possuem as características apontadas por Rodrigues (2008), quando afirma que existe uma série de aspectos intrínsecos à figura do empreendedor, sendo ele um agente de mudanças,

Como limitações da pesquisa destaca-se a abrangência, uma vez que o mesmo limitou-se a bares localizados na cidade de Belo Horizonte/MG, Brasil.

Sugerem-se para futuros estudos que se contemplem a interseção entre empreendedorismo e marketing para o segmento de bares no Brasil, um setor altamente dinâmico e que é responsável por mais de $23 \%$ do total de empreendimentos no país.

\section{Referências}

ALVES, G. Trabalho e reestruturação produtiva no Brasil neoliberal: precarização do trabalho e redundância salarial. Revista Katálysis, v. 12, n.2, p. 188-197, 2009.

BARDIN, L. Análise de conteúdo. Lisboa: Edições 70, 2006.

BATESON, J; HOFFMAN, D. Marketing de Serviços. Porto Alegre: Bookman, 2003.

BLOCK, J. H.; SANDNER, P. Necessity and opportunity entrepreneurs and their duration in self-employment: evidence from German micro data. Journal of Industry Competition and Trade, v.9, n.2, p. 117-137, 2009. 
Universidade do Estado de Santa Catarina

Centro de Educação Superior do Alto Vale do Itajaí

BLOCK, J. H.; WAGNER, M. Necessity and opportunity entrepreneurs in Germany: characteristics and earnings differentials. Schmalenbach Business Review, v.62 (2), p. 154-174, 2010.

BRASIL. Decreto Lei $\mathbf{n}^{\mathbf{0}}$ 5.028, de 31 de março de 2004. Altera os valores dos limites fixados nos incisos I e II do art. $2^{\circ}$ da Lei $\mathrm{n}^{\circ}$ 9.841, de 05 de outubro de 1999, que instituiu o Estatuto da Microempresa e da Empresa de Pequeno Porte. Diário Oficial da República Federativa do Brasil, Brasília, p. 06, de $1^{\text {o }}$ de abril de 2004, 2004.

BRASIL. Lei complementar $\mathbf{n}^{\mathbf{0}}$ 123, de 12 de dezembro de 2006. Disponível em: http://www.planalto.gov.br/ccivil_03/leis/lcp/lcp123.htm. Acesso em: 16 dez. 2014.

CZINKOTA, M. R. Marketing: As Melhores Práticas. Porto Alegre: Bookman, 2001.

CRESWELl, J. W. Projeto de Pesquisa: métodos qualitativo, quantitativo e misto (2 ed.). Porto Alegre: Artmed, 2007.

DEGEN, R. J. O empreendedor: empreender como opção de carreira. São Paulo: Pearson Pretince Hall, 2009.

DENZIN, N. K.; LINCOLN, Y. S. Planejamento da pesquisa qualitativa: Teorias e abordagens. Porto Alegre: Artmed, 2010.

DOLABELA, F. O segredo de Luísa. São Paulo: Editora de Cultura, 1999.

DORNELAS, J. C. A. Empreendedorismo: Transformado ideias em negócios. Rio de Janeiro: Campus, 2001.

DRUCKER, P.F. Inovação e Espírito Empreendedor: prática e princípios. São Paulo: Pioneira Thomson, 2005.

FESTINALLI, R.C. Estratégias empresariais em empresas do contexto empreendedor: O caso da indústria laticínio vila nova. Apresentando no encontro de estudos estratégicos da associação nacional dos programas de pós-graduação em administração, Anais... Curitiba, ANPAD, 2003.

FILION, L. J. O Planejamento do seu sistema de aprendizagem empresarial: identifique uma visão e avalie o seu sistema de relações. RAE Revista de Administração de Empresas, v.31, n.3, 63-71, 1999.

FITZSIMMONS, J. A; FITZSIMMONS, M. J. Administração de serviços: operações, estratégia e tecnologia de informação (4. ed.). Porto Alegre: Bookman, 2010.

GIL, A. C. Métodos e Técnicas de pesquisa social (5. ed.). São Paulo: Atlas, 1999.

GLOBAL ENTREPRENEURSHIP MONITOR - GEM. Empreendedorismo no Brasil, 2011. Disponível em: http://gestaoportal.sebrae.com.br/customizado/estudos-e-pesquisas/temasestrategicos/empreendedorismo/Livro\%20GEM\%20Brasil\%202011.pdf. Acesso em: 02 fev. 2015.

GLOBAL ENTREPRENEURSHIP MONITOR - GEM. Empreendedorismo no Brasil 2012. Curitiba: IBQP, 2012. 
Universidade do Estado de Santa Catarina

Centro de Educação Superior do Alto Vale do Itajaí

HITT, M. A.; IRELAND, R. D.; HOSKISSON, R. E. Strategic Management: Competitiveness \& Globalization (9 ed.). South-Western: Cengage Learning, 2011.

HUNT, S. D. Marketing Theory: Foundations, controversy, strategy, resource-advantage theory. New York: M. E. Sharpe, 2010.

INSTITUTO BRASILEIRO DE GEOGRAFIA E ESTATÍSTICA. Estatística de empreendedorismo 2012. Brasilia: IBGE, 2012.

KOTLER, P. Administração de Marketing: Edição do novo milênio. São Paulo: Prentice Hall, 1998.

KUEMMERLE, W. Home base and knowledge management in international ventures.Journalof Business Venturing, v.17, n.2, p. 99-122, 2002.

MIGUEL, P. SALOMI, G. Uma revisão dos modelos para medição da qualidade em serviços. Gestão e Produção, v.14, n.1, p. 12-30, 2004.

MINER, J. B. A psychological typology and its relationship to entrepreneurial success.Entrepreneurship\& Regional Development, v.9, n.1, p. 319-334, 1997.

MINTZBERG, H. O processo da estratégia ( $3^{\circ}$ ed.) Porto Alegre: Bookman, 2001.

OLIVEIRA, J. R. C. Longevidade empresarial e características comportamentais empreendedoras: uma análise das micro e pequenas empresas de Teófilo Otoni e região (Dissertação de Mestrado). Faculdade Novos Horizontes, Belo Horizonte, 2010.

PETER, J. P; OLSON, J C. Comportamento do consumidor e estratégia de marketing (8 ed.). São Paulo: McGraw-Hill, 2009.

RODRIGUES, S. Empreendedorismo (1 ${ }^{\text {a }}$ Ed.). Lisboa: Anje, 2008.

SCHUMPETER, J. A.A teoria do desenvolvimento econômico: uma investigação sobre lucros, capital, crédito, juros e o ciclo econômico. São Paulo: Nova Cultural, 1996.

SERVIÇO BRASILEIRO DE APOIO ÀS MICRO E PEQUENAS EMPRESAS. Pequenos Negócios no Brasil. Brasília: SEBRAE, 2013.

STEVENSON, H. H; GUMPERT, D.E.The heart of entrepreneurship.Havard Business Review, v.63, n.2, p. 85-94, 1985.

TRIVIÑOS, A. N. S. Introdução à pesquisa em ciências sociais: pesquisa qualitativa em educação. São Paulo: Atlas, 1992.

VALE, G. M. V.; CORRÊA, V. S.; REIS, R. F. Motivações para o empreendedorismo: necessidade versus oportunidade? Revista de AdministraçãoContemporânea - RAC, v.18, n.3, p. 311-327, 2014.

WILLIAMS, C. C. The motives of off-the-books entrepreneurs: necessity-or opportunity-driven? Springer Science, v.5, n.2, p. 203-217, 2008. 
YIN, R. K. Estudo de caso: planejamento e métodos (4.ed.) Porto Alegre: Bookman, 2010.

ZEITHAML, V.; BERRY, L; PARASURAMAN, A. A. Conceptual Model of Service Quality and Its Implications for Future Research.Journal of Marketing, v. 49, n.1, p. 41-50, 1988. 